\title{
Treating head and neck cancer-A multidisciplinary effort
}

\author{
Gabriele Gamerith · Thorsten Fuereder
}

(C) Springer-Verlag GmbH Austria, part of Springer Nature 2020

Head and neck (HNC) is the tenth most common cancer worldwide with over 650,000 new cases per year [1-3]. The major risk factors for development of squamous cell HNC comprise alcohol and tobacco consumption [4]. During the last few decades human papilloma virus (HPV) infection has been identified to contribute to the development of oropharyngeal HNC in a younger subgroup of patients [5]. This population shows a more favorable prognosis compared to HPV-negative disease [5]. Standard treatment options for HNC independent of HPV status include surgery, standard radiation, chemo- or bioradiation and chemotherapy.

Therefore, a multidisciplinary team, involving radiation oncologists, medical oncologists, head and neck surgeons and nutritionists is necessary for the optimal management of these patients throughout the course of their disease. In an effort to improve the outcome both at an early and at an advanced (or even recurrent/metastatic) stage novel treatment concepts have been introduced during the last couple of years.

Minimally invasive surgical techniques such as transoral robotic surgery (TORS) have contributed to reduced morbidity rates, shorter hospital stays and faster recovery times in oropharyngeal cancer patients without endangering the oncological outcomes.

\footnotetext{
G. Gamerith, MD $(\bowtie)$

Department of Internal Medicine V, Hematology and Medical Oncology, Medical University Innsbruck, Anichstraße 35, 6020 Innsbruck, Austria gabriele.gamerith@i-med.ac.at
}

Assoc. Prof. PD Dr. T. Fuereder ( $₫)$

Department of Medicine I and CCC, Division of Oncology,

Medical University Vienna, Währinger Gürtel

18-20, 1090 Vienna, Austria

thorsten.fuereder@meduniwien.ac.at
For tumors, however, which are located near the skull base or in a previously irradiated field, particle therapy employing protons can provide a novel treatment option accompanied with reduced side effects compared to conventional photon therapy. In addition to protons, carbon ions recently entered the stage providing benefits for the treatment of radioresistant histologies such as adenoid cystic carcinomas.

Despite the improvements outlined above, recurrence rates of stage III/IV disease after curative therapy is about $50 \%$ in the first 2 years of follow-up [6, 7]. For patients, who are not amenable to salvage surgery, only limited palliative treatment options such as systemic chemotherapy and targeted treatments exist resulting in a median overall survival of 10 months [8].

With the advent of immuno-oncology and the approval of immune checkpoint inhibitors, which target the interaction between PD-1 and PDL-1, the prognosis of HNC patients in the recurrent/metastatic setting has improved substantially.

However, we must not forget that HNC is a heterogeneous disease: While $90 \%$ of HNC are squamous cell carcinomas, salivary gland carcinomas (SGC) account for approximately $6-8 \%$ of HNC. Since the evidence from clinical trials is sparse, metastatic SGC pose a therapeutic challenge. The increasing availability of next generation sequencing (NGS) and intensive research efforts shed light onto the molecular alterations of SGC, which can be exploited utilizing targeted therapies such as trastuzumab in HER2-positive SGC or hormone-based treatment options in androgen-receptor positive cases.

Finally, the relevance of nutritional counseling has to be emphasized: Since HNC patients are frequently malnourished, early intervention is essential in order to improve not only quality of life, but also oncological outcome. 
We want to thank the experts who contributed to this series and provided an update about the current developments for the treatment of HNC from the surgeon's, radiation oncologist's, medical oncologist's and nutritionist's point of view [9-13].

Conflict of interest G. Gamerith received travel and/or research grants from ROCHE, MERCK, TAKEDA, MSD, AMGEN, BMS, and BI and has worked as an advisor for MERCK and AMGEN. T. Fuereder declares that he has no competing interests.

\section{References}

1. Jemal A, Bray F, Center MM, Ferlay J, Ward E, Forman D. Global cancer statistics. CA Cancer J Clin. 2011;61:69-90.

2. Marur S, Forastiere AA. Head and neck cancer: changing epidemiology, diagnosis, and treatment. Mayo Clin Proc. 2008;83:489-501.

3. Pfister DG, Ang KK, Brizel DM, et al. Head and neck cancers, version 2.2013. Featured updates to the NCCN guidelines. J Natl Compr Canc Netw. 2013;11:917-23.

4. World Health Organization, International Agency for Research on Cancer. Alcohol consumption and ethyl carbamate. IARC monographs on the evaluation of carcinogenic risks to humans, Vol.96. 2010. pp.3-1383.

5. Tornesello ML, PerriF, BuonaguroL, IonnaF, BuonaguroFM, Caponigro F. HPV-related oropharyngeal cancers: from pathogenesis to new therapeutic approaches. Cancer Lett. 2014;351:198-205.

6. Leemans CR, Tiwari R, Nauta JJ, van der Waal I, Snow GB. Recurrence at the primary site in head and neck cancer and the significance of neck lymph node metastases as a prognostic factor. Cancer. 1994;73:187-90.
7. Sturgis EM, Miller RH. Second primary malignancies in the head and neck cancer patient. Ann Otol Rhinol Laryngol. 1995;104:946-54.

8. Vermorken JB, Specenier P. Optimal treatment for recurrent/metastatic head and neck cancer. Ann Oncol. 2010;21(Suppl7):vii252-vii61.

9. Strobl A, Hartl M, Burian M. Transoral robotic surgery in head and neck cancer. memo. 2020;13(4). https://doi.org/ 10.1007/s12254-020-00638-5.

10. GeorgP.Particletherapyinhead and neckcancer-expanding therapeutic options. memo. 2020;13(4). https://doi.org/ 10.1007/s12254-020-00623-y.

11. Kloppenburg M, Mildner F, Kasseroler MT, Dejaco D, Amann A. Established treatment concepts for recurrent or metastatic head and neck squamous cell carcinoma (R/M HNSSC). memo. 2020;13(4). https://doi.org/10. 1007/s12254-020-00645-6.

12. Minichsdorfer C. Systemic therapy for metastatic salivary gland tumors-challenges and novel concepts. memo. 2020;13(4). https://doi.org/10.1007/s12254-020-00614-z.

13. Wagner C. Nutritional management during treatment for head and neck cancer. memo. 2020;13(4). https://doi.org/ 10.1007/s12254-020-00613-0.

Publisher's Note Springer Nature remains neutral with regard to jurisdictional claims in published maps and institutional affiliations.

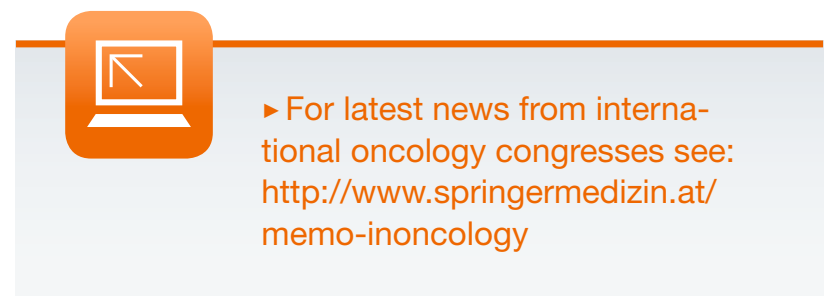

